\title{
RUANG BERSAMA UNTUK MANUSIA DAN ANJING
}

\author{
Merrie Ivana Uktolseja ${ }^{1)}$, Budi Adelar Sukada ${ }^{2)}$
}

1) Program Studi S1 Arsitektur, Fakultas Teknik, Universitas Tarumanagara, merrieivanauktolseja@yahoo.com

2) Program Studi S1 Arsitektur, Fakultas Teknik, Universitas Tarumanagara, budisukada@yahoo.com

\begin{abstract}
Abstrak
Kini, anjing adalah hewan berkaki empat yang banyak diminati untuk dipelihara karena memelihara hewan merupakan salah satu cara menghilangkan stress. Jumlah pemilik anjing di Jakarta setiap tahunnya meningkat, namun ruang publik untuk para pemilik anjing yang ingin berpergian dan menghabiskan waktu luang dengan anjing peliharaannya masih terbatas. Maka dari itu, sesuai namanya, "Ruang Bersama untuk Manusia dan Anjing" bertujuan untuk menciptakan tempat di mana manusia dapat menghabiskan waktu luang dengan anjing peliharaan tanpa batas di antara mereka. Lokasi yang dipilih untuk proyek ini adalah Kebon Jeruk, Jakarta Barat, karena berdasarkan data yang ada, Jakarta Barat merupakan area dengan jumlah kepemilikan anjing tertinggi dibandingkan dengan area lain di Jakarta. Metode perancangan dimulai dengan pengumpulan data melalui observasi dan studi literatur untuk membantu mendapatkan informasi yang dibutuhkan. Kemudian, proses perancangan bentuk bangunan dilakukan dengan pendekatan ikonik yang merespon bentuk muka kawasan sekitar tapak. Hasil dari perancangan ini merupakan sebuah fasilitas multifungsi yang terdiri dari fasilitas ruang komunal, restoran, dan kafe untuk manusia, serta fasilitas ruang bermain, kolam renang, perawatan, dan hotel untuk anjing. Proyek ini diharapkan menjadi tempat ketiga yang dapat mengurangi tingkat stress masyarakat yang membutuhkan istirahat dari rutinitas sehari-hari dan mewadahi aktivitas pecinta anjing, di mana manusia dan anjing dapat berkumpul dan bersosialisasi.
\end{abstract}

Kata kunci: anjing; bersosialisasi; manusia; multifungsi

\begin{abstract}
Nowadays, dogs are four-legged animal that are much in demand to be kept as pets because having a pet is one way to relieve stress. The number of dog's owners in Jakarta is rising every year, but the public place for dog owner's who wants to travel with their dogs is still lacking. Therefore, just like its' name, "Human and Canine Sharing Space" intends to creat a place where human can spend their spare time with dogs without any boundary between them. The location chosen for this project is Kebon Jeruk, West Jakarta, because based on data, West Jakarta is the area with the highest number of dog ownership compared to other areas in Jakarta. The design method starts with collecting data by observation and literature study to help getting information needed. Then, the building design process is using the iconic aproach which responded to the area around the site. The outcome of this design process is a multifunctional facility which consists of communal space, restaurant and café for human, as well as playroom, swimming pool, grooming area and hotel for dogs. This project is expected to be a third place that can reduce society's stress level that needed a break from their everyday routines and accomodating dog lovers' activities, where human and dogs can gather and socialize.
\end{abstract}

\section{Keywords: dogs; human; multifunctional; socialize}

\section{PENDAHULUAN}

Kehidupan manusia identik dengan kecenderungan melakukan hal yang sama hampir setiap harinya. Tuntutan pekerjaan yang tinggi menjadi salah satu penyebab stress di Jakarta. Indonesia merupakan salah satu negara yang memiliki jam kerja tertinggi, yaitu lebih dari 60 jam dalam satu minggu, sementara rata-rata hanya 40 jam dalam seminggu. Jakarta juga menjadi salah satu negara yang disebut most stressful city di Asia. 
Salah satu alternatif untuk menghilangkan stress dan kejenuhan adalah memiliki hewan peliharaan. Fisik dan tingkah laku hewan pada umumnya dianggap lucu dan menarik oleh pemiliknya (pet owner), maka dari itu hewan peliharaan berpotensi membuat pet owner merasa senang yang akhirnya mengurangi kadar stress dan kejenuhan dari rutinitas sehari-hari. Menurut penelitian yang dilakukan oleh Scribani, memeliharan hewan dapat menurunkan tingkat hormon kortisol (hormon penyebab stress) dan meningkatkan hormon oksitosin (hormon yang meningkatkan rasa bahagia). Penelitian yang dilakukan oleh McConnell juga menyatakan bahwa memelihara hewan peliharaan memberi manfaat untuk psikologis, yaitu pet owner lebih menikmati hidup, sejahtera, sehat, dan kepuasan terhadap cinta kasih yang lebih tinggi dibandingkan non pet owner, serta memberi manfaat fisiologis yang dibuktikan bahwa jumlah pet owner yang meninggal akibat serangan jantung lebih sedikit dibandingkan non pet owner. Pet owner juga memiliki tingkat depresi, rasa khawatir, rasa kesepian, takut, dan sifat egois yang lebih rendah daripada non pet owner.

Tren memelihara hewan yang semakin digemari di Indonesia menyebabkan potensi pasar hewan peliharaan juga terus berkembang. Menurut Majalah Marketing, menyatakan bahwa sejak tahun 2005, pecinta kucing ras di Indonesia mulai meningkat. Indonesian Kennel Klub (IKK) juga menyatakan bahwa kepemilikan anjing ras pada tahun 2016 meningkat 21\% dari tahun 2014 dan angka tersebut terus meningkat secara konsisten beberapa tahun terakhir dengan ukuran 10 pt beserta tahun pembuatan tabel satu spasi di bagian bawah tabel rata kiri, seperti contoh berikut:

Tabel 1. Jumlah Pemilik Anjing di Indonesia

\begin{tabular}{cc}
\hline Tahun & Jumlah Pemilik Anjing \\
\hline 2014 & 328.348 \\
\hline 2015 & 265.670 \\
\hline 2016 & 398.886 \\
\hline
\end{tabular}

Sumber: Federation Cynologique Internationale (FCI) \& Indonesia Kennel Klub (IKK)

Memelihara hewan bukan hanya menjadi sekedar hobi, namun hewan peliharaan itu sendiri juga dianggap sebagai teman atau keluarga. Berdasarkan hasil penelitian yang dilakukan Associated Press (2010) menjelaskan bahwa 50\% pet owners memperlakukan hewan peliharaan mereka sebagai anggota keluarga, 30\% tidur bersama hewan peliharaannya, dan 35\% hewan peliharaan turut serta dalam foto keluarga. Anjing dan kucing adalah jenis hewan berkaki empat yang paling banyak dipelihara di Indonesia. Banyak faktor dalam memilih hewan peliharaan, salah satunya adalah agama. Mayoritas masyarakat Indonesia beragama Muslim, maka jumlah kepemilikan anjing tidak sebanyak kepemilikan kucing.

Tabel 2. Jumlah Pemilik Hewan Peliharaan di Indonesia

\begin{tabular}{cc}
\hline Hewan & Jumlah Pemilik \\
\hline Anjing & $15,5 \%$ \\
\hline Kucing & $37,0 \%$ \\
\hline Burung & $19,3 \%$ \\
\hline Kelinci & $6,5 \%$ \\
\hline Hamster & $3,7 \%$ \\
\hline Ikan Mas & $15,6 \%$ \\
\hline Tropical Fish & $3,5 \%$ \\
\hline Reptil atau Amfibi & $3,5 \%$ \\
\hline Serangga & $0,4 \%$ \\
\hline
\end{tabular}

Sumber: insight.rakuten.com/pet-market-in-asia

Hewan juga merupakan makhluk hidup yang juga perlu bermain dan bersosialisasi seperti manusia. Kegiatan yang biasa dilakukan oleh pet owners adalah mengajak peliharaan mereka keluar rumah atau ke tempat umum yang tidak melarang membawa 
hewan peliharaan. Walaupun jumlah kepemilikan anjing di Indonesia selalu bertumbuh, tetapi tempat yang dapat dimanfaatkan oleh anjing dan pemiliknya yang nyaman masih terbatas, dan setiap tempat tentunya masih memiliki kekurangan masing-masing. Ada pilihan tempat seperti Pet Kingdom di Serpong, Vodka and Latte di Kemang, dan Rumah Guguk di Bandung yang menyediakan layanan grooming bagi hewan dan area bermain, namun area ini tidak dapat digunakan secara bebas. Pilihan lainnya adalah dog friendly café yang mengizinkan pengunjung membawa anjing peliharaannya.

Namun, kegiatan yang dapat dilakukan oleh anjing sangat sedikit karena biasanya anjing yang dibawa akan tetap diikat dan menunggu di dekat pemiliknya. Selain kedua pilihan itu, ada pilihan yang lebih baik yaitu mengunjungi dog friendly park seperti Tribeca Park di Grogol dan Como Park di Kemang, namun kelemahannya terdapat pada keamanan karena tidak ada pemisah antara anjing berukuran besar dan kecil. Maka dari itu, proyek ini bertujuan untuk menggabungkan keuntungan-keuntungan dari berbagai jenis ruang publik yang bersifat dog friendly dengan meminimalisir kekurangan-kekurangan yang ada pada masing-masing tempat.

Menurut Smith (2007), berkunjung ke dog park bermanfaat untuk memotivasi pemilik anjing untuk keluar rumah dan berolahraga dengan anjingnya. Selain itu, dapat membantu orang berinteraksi dengan orang lainnya dengan minat yang sama, ditambah dengan bantuan dengan adanya anjing peliharaan yang menjadi topik pembicaraan diharapkan, maka diharapkan akan meningkatkan hubungan antar manusia. Sedangkan untuk anjing itu sendiri bermanfaat untuk memberi mereka kesempatan bersosialisasi dengan anjing lainnya.

Meskipun berdasarkan data jumlah pemilik kucing lebih banyak dari pemilik anjing, namun dalam proyek Open Architecture for the Third Place ini akan fokus untuk membuat area rekreasi berupa fasilitas multifungsi yang ditujukan terutama untuk pecinta anjing dan anjing peliharaan mereka karena mempertimbangkan perbedaan karakter antara anjing dan kucing sebagai berikut: (Pet, 2019)

a. Kucing lebih mandiri daripada anjing. Kucing tidak bergantung banyak pada manusia, selain untuk kebutuhan makanan. Sementara anjing dahulu hidup dengan berkelompok, sehingga kini anjing melihat pemiliknya seperti pemimpin. Anjing senang berinteraksi dengan pemiliknya sebagai cara untuk berhubungan dengan "pemimpin" mereka.

b. Kucing tidak dikenal sebagai hewan yang atletik. Berbeda dengan kucing, anjing membutuhkan olahraga secara rutin. Banyak anjing ras yang menyukai berenang, berlari, bahkan mendaki dengan pemiliknya.

c. Kucing adalah hewan nocturnal. Kucing lebih aktif bermain di malam hari, sedangkan anjing aktif bermain di siang hari.

\section{KAJIAN LITERATUR}

Menurut Esra Akcan, penulis buku Open Architecture: Migration, Citizenship and the Urban Renewal of Berlin-Kreuberg by IBA-1984 / 87, "openness" adalah nilai dasar modern yang baru. Open architecture didasarkan dari kumpulan pemikiran yang berbeda-beda ke dalam desain, artinya terkait dengan fleksibilitas dan kolaborasi, keberagaman makna, demokrasi dan pluralitas, desain sumber terbuka, perluasan hak asasi manusia dan kewarganegaraan sosial, dan solidaritas transnasional. Akcan mengemukakan bahwa open architecture berhubungan erat dengan open city dan open society yang dapat membuat kota lebih baik. Kedua hal ini mengaitkan dengan sisi kehidupan informal di kota di mana masyarakat berkumpul dan berinteraksi di suatu tempat tanpa memperhatikan kualitas lingkungan yang ada. Di kota terdapat batas-batas yang akhirnya membuat bangunan dan lingkungan tidak berinteraksi karena adanya perbedaan kelompok. Maka dari itu, kota memerlukan adanya open architecture untuk menghapuskan batas-batas yang ada dengan menggunakan fleksibilitas dan menyelesaikan perbedaan ke dalam ruang fisik. Ruang fisik yang dibentuk bisa berupa third place, di mana salah satu cirinya juga mempunyai sifat openness. 
Dalam kehidupan sehari-hari manusia tentunya membutuhkan tempat tinggal dan pendidikan atau pekerjaan. Tempat tinggal merupakan first place dan sekolah, kampus, atau kantor adalah second place. Menurut pengertian dari Oldenburg, third place atau tempat ketiga adalah sebuah lingkungan sosial yang terpisah dari first place dan second place, di mana orang banyak menghabiskan waktu luangnya. Oldenburg menyarankan kehidupan yang seimbang antara ketiga bidang: home life, the workplace, dan sociable places. Third place adalah tempat yang bermanfaat untuk mengurangi stress, rasa kesepian, dan keterasingan. Contoh dari third place antara lain adalah barbershop, community center, senior center, kafe, dll.

Beberapa karakteristik third place adalah:

a. Pengunjung dari third place tidak mempunyai kewajiban untuk datang ke tempat tersebut.

b. Sosial atau status ekonomi tidak mempengaruhi kegiatan di dalam third place, semua pengunjung dianggap setara.

c. Pembicaraan yang menyenangkan adalah fokus utama dari third place, walaupun itu bukan satu-satunya kegiatan yang dapat dilakukan.

d. Third place harus mudah diakses dan menjadi sebuah tempat yang memenuhi kebutuhan.

e. Sebuah third place memiliki pengunjung yang datang secara rutin. Pengunjung ini yang menciptakan suasana pada third place dan berpotensi mendatangkan pengunjung baru dan membuat mereka merasa disambut dengan baik.

f. Third place harus menjadi tempat di mana orang dapat menjadi diri sendiri.

g. Third place harus menjadi tempat yang menyenangkan dan memiliki atmosfir yang ceria.

h. Pengunjung third place akan merasa nyaman seperti di rumah.

(Oldenburg, 1991)

Anjing dan manusia sudah berteman kurang lebih sejak 10.000 tahun yang lalu. Ada dua teori yang berbeda tentang anjing. Pertama, anjing adalah keturunan dari serigala. Kedua, anjing adalah keturunan kewan buas lainnya yang sudah punah. Dahulu, manusia berburu dengan bantuan anjing liar. Ini menjadi simbiosis mutualisme karena anjing-anjing liar juga mendapat makanan dari sisa-sisa manusia. Anjing-anjing liat akhirnya menjadi jinak, serta menurunkan perubahan karakteristik ke keturunannya, antara lain perubahan sifat dari indera penglihatan, pendengaran, dan penciuman. Anjing juga akhirnya dilatih untuk berbagai keterampilan. American Kennel Club (AKC) kini mengenal sekitar 150 jenis anjing yang terbagi pula menjadi beberapa kelompok, yaitu anjing kecil, anjing pekerja, anjing penggembala, anjing untuk olahraga dan tidak untuk olahraga, dan anjing mainan.

Kebutuhan anjing antara lain adalah tidur di area yang luas dan nyaman, bermain, buang air, berlari, bersosialisasi, perawatan tubuh, makan, dan minum. Dari penelitian McConnell dapat disimpulkan bahwa hewan peliharaan memberi dampak yang baik bagi pemiliknya, baik dari segi fisiologis, maupun psikologi. Berdasarkan penelitian oleh Euromonitor International pada tahun 2017, beberapa faktor yang menyebabkan masyarakat memelihara hewan peliharaan, antara lain adalah pernikahan yang tertunda, kehamilan yang tertunda, faktor penuaan, meningkatnya masyarakat yang memutuskan untuk tinggal sendiri, media sosial, dan self-branding. Maka dari itu hewan juga menjadi anggota keluarga, aksesoris, dan kebanggaan tersendiri untuk pemiliknya. Atas dasar rasa sayangnya terhadap peliharaan tersebut tentunya akan selalu diawasi kesehatan, kebersihan, dan kebutuhannya.

Dog park memiliki manfaat bukan hanya bagi anjing, namun juga manusia dan masyarakat. Manfaat untuk anjing antara lain adalah untuk latihan fisik dan mental, sosialisasi, serta menciptakan lingkungan yang aman untuk bermain. Manfaat untuk manusia adalah sebagai untuk para pemilik anjing bersosialisasi, selain itu masyarakat lansia dan yang memiliki disabilitas juga dapat membawa anjing mereka untuk berolahraga, dan menunjang kesejahteraan sosial dan kesehatan mental. Manfaat untuk masyarakat menciptakan lingkungan dengan kepemilikan anjing yang bertanggung jawab, menjadi pilihan rekreasi yang terjangkau, serta menjadi tempat istirahat untuk komunitas yang berpergian dengan anjingnya. 
Namun, dengan segala keuntungan yang diperoleh, ada juga resiko yang harus diperhatikan dalam membuat bangunan dengan yang dog-friendly, antara lain adalah keamanan hewan dan manusia, hubungan anak-anak dan anjing, perilaku anjing pengunjung, resiko kesehatan, pengaruhnya ke lingkungan setempat seperti polusi udara dan suara, serta kebutuhan lahan parkir karena $68 \%$ pengunjung dog park datang menggunakan mobil pribadi, 31\% berjalan kaki, dan 1\% lainnya. (Dog Park Survey, Hazel and Thomsen, n.d.)

\section{METODE}

Metode yang digunakan dalam perancangan ini adalah pendekatan ikonik, yaitu pendekatan dengan bentuk yang dapat diterima oleh sekitarnya. Berbeda dengan metode arsitektur ikonik, pendekatan ikonik bukan bertujuan membentuk bangunan yang memiliki bentuk aneh dan berbeda. Pendekatan ikonik memiliki keterkaitan dengan masyarakat karena masyarakat sudah "kenal" dengan tampilan dari bangunan tersebut. Sedangkan arsitektur ikonik biasanya akan menjadi penanda atau ciri khas dari suatu tempat atau daerah karena tampilannya, namun tidak sesuai dengan image dari kawasan, sehingga terkesan egois.

Perancangan berawal dengan pengumpulan data dengan studi literatur dan observasi. Dengan studi literatur, terkumpul data yang mendukung bahwa bangunan ini menjadi sesuatu yang dibutuhkan di masa kini dan berpotensi untuk menjadi ruang publik yang berguna di masa mendatang juga. Data literatur yang ada berupa kuantitatif yang menunjukan peningkatan jumlah kepemilikan anjing di Indonesia dan di Jakarta, untuk menentukan lokasi yang cocok untuk proyek ini. Selain itu, studi literatur juga dilakukan untuk mengetahui hal-hal yang perlu diperhatikan dalam membuat bangunan yang dog-friendly, serta bagaimana pemeliharaannya. Kemudian, observasi dilakukan pada ruang publik yang serupa yang sudah ada untuk mengambil kelebihan-kelebihan ke dalam proyek ini, serta mengurangi kelemahan-kelemahan yang ada.

Setelah data terkumpul, dilakukan analisis sirkulasi pada tapak untuk menentukan letak jalur masuk dan keluar dari tapak. Gubahan kemudian dilakukan dengan merespon bentuk tapak agar dapat memanfaatkan luasan yang tersedia dengan maksimal. Ketinggian gubahan ditentukan dengan melihat dan merespon ketinggian bangunan di masing-masing sisi tapak.

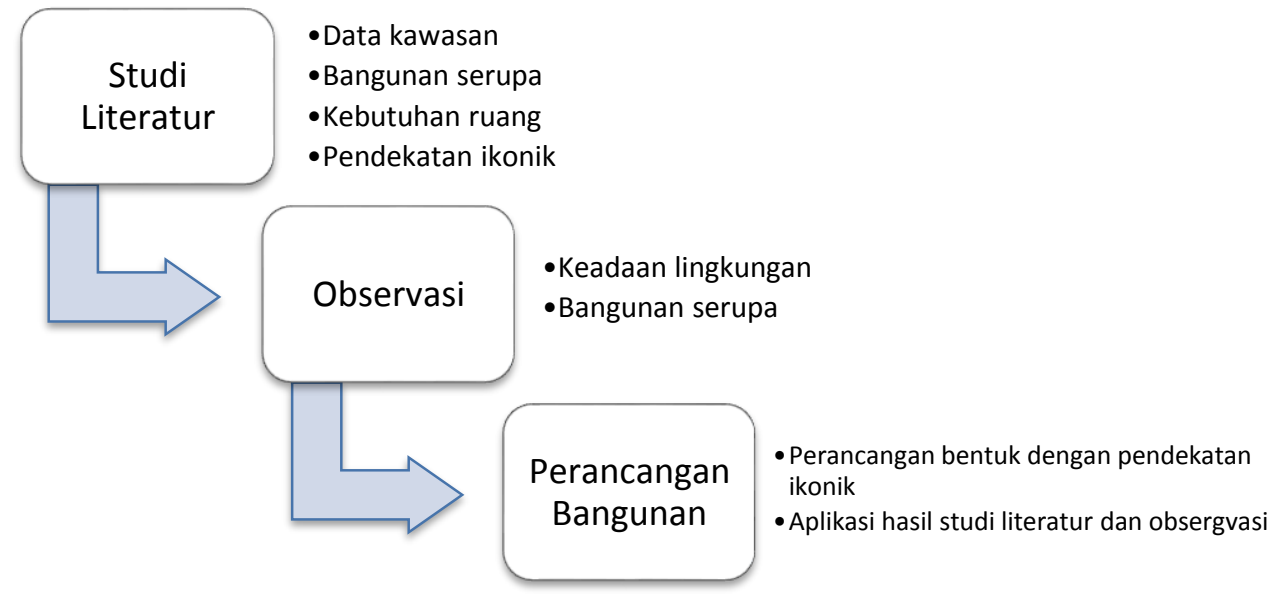

Gambar 1. Skema Metode Perancangan Sumber: Penulis, 2019

\section{DISKUSI DAN HASIL}

Dari data yang ada dan beberapa pertimbangan, tapak yang terpilih berada di Kebon Jeruk, Jakarta Barat karena jumlah pemilik anjing terbanyak adalah di Jakarta Barat. Tapak yang dipilih juga terletak berhimpitan dengan rumah warga sehingga diharapkan selain dimanfaatkan oleh para pemilik anjing, tempat ini juga dapat dimanfaatkan warga sekitar sebagai tempat rekreasi dan berkumpul. Bagian depan tapak merupakan jalan raya selebar 8 meter, terdiri dari 2 arah dengan masing-masing 1 lajur. Bagian kanan (barat) tapak adalah jalan kecil dengan lebar 2 
meter yang biasa dilalui oleh warga dari perumahan di belakang tapak dengan jalan kaki atau menggunakan sepeda motor. Di bagian kiri (timur) tapak adalah tanah kosong yang dipenuhi pepohonan. Di bagian belakang (selatan) tapak adalah pemukiman dengan ketinggian bangunan 1-2 lantai. Karena lokasi tapak yang berhimpitan langsung dengan pemukiman, bangunan ini tentunya menjadi tempat rekreasi yang memadai, aman, dan terjangkau. Selain itu, bangunan ini juga terletak di pinggir jalan raya dan jalan tol sehingga mudah juga dijangkau dengan kendaraan.
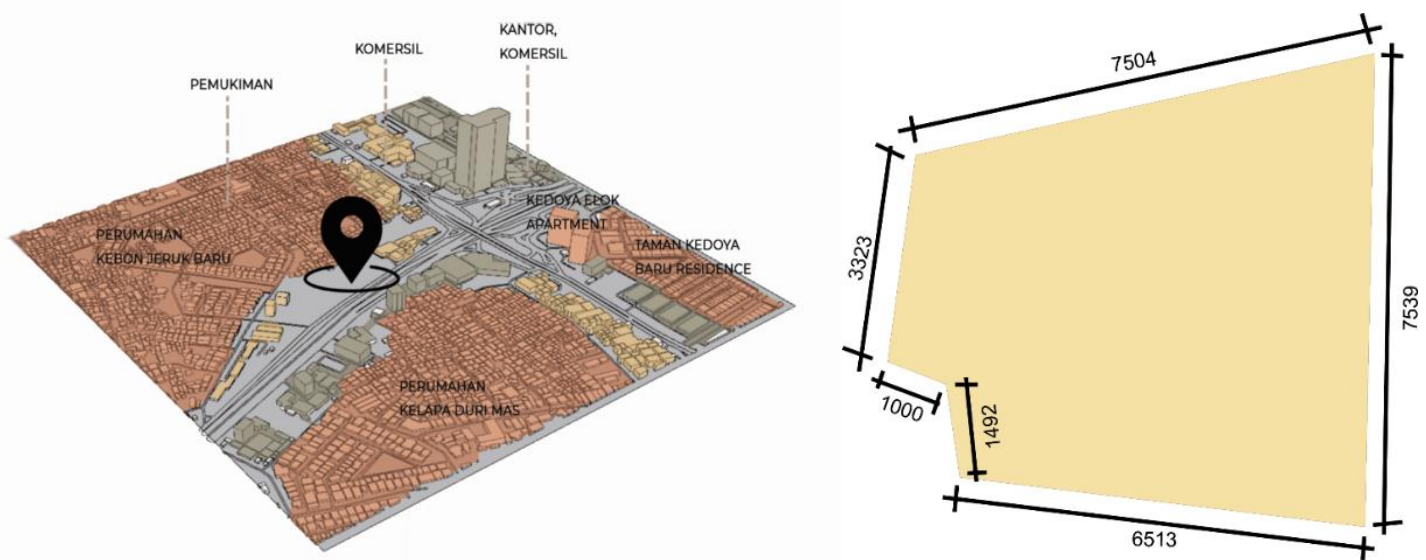

Gambar 2. Lokasi Tapak

Sumber: Penulis, 2019

Dari analisis sirkulasi tapak, ditentukan tiga sirkulasi untuk keluar masuk tapak. Satu pintu keluar-masuk untuk pengunjung di bagian kanan depan tapak, satu di bagian belakang yang merupakan terusan dari jalan kecil yang sudah ada di belakang tapak. Gubahan kemudian diberikan ketinggian dengan merespon bentuk dan kawasan tapak. Bagian yang menghadap ke depan dan ke area terbuka dibuat berundak-undak untuk menyesuaikan human scale.

Area barat (kanan) tapak menjadi area untuk akses kendaraan pengunjung (mobil dan motor), area timur (kiri) menjadi area untuk kendaraan servis dan akses menuju ke basement. Program ruang utama yang dibuat ditujukan untuk memenuhi kebutuhan-kebutuhan anjing peliharaan seperti bermain, bersosialisasi, perawatan, dan istirahat, serta memenuhi kebutuhan manusia sebagai pemilik anjing peliharaan tersebut, seperti makan, bersosialisasi, dan istirahat. Zoning program ruang-ruang utama dibuat secara vertikal. Masing-masing lantai memiliki 1 fungsi yang utama, di mana bagian bawah (lantai 1 dan 2 lebih difokuskan untuk fasilitas yang dominan dimanfaatkan manusia seperti ruang komunal, restoran, dan kafe. Lantai 3 sampai 7 difokuskan untuk fasilitas yang dominan dimanfaatkan untuk kebutuhan anjing, yaitu area bermain indoor, kolam renang, area perawatan, dan hotel. Ruang di bawah sifatnya lebih terbuka, semakin ke atas semakin tertutup (privat). Di lantai paling atas adalah area yang paling privat yang terdiri dari ruang karyawan, kantor pengelola, dan gudang, serta terdapat area untuk meletakan reservoir atas dan outdoor AC. 


\section{PROSES DESAIN}

GUBAHAN MERESPON BENTUK TAPAK DAN SEKITARNYA

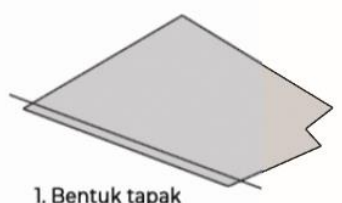

1. Bentuk tapak

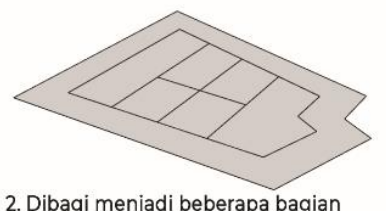

2. Dibagi menjadi beberapa bagian

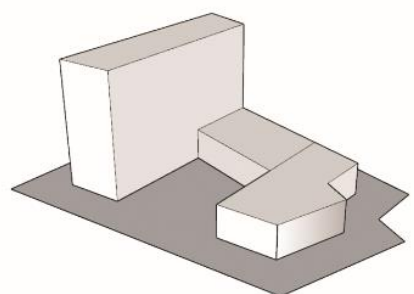

3. Diberi ketinggian yang merespon

lingkungan sekitar tapak

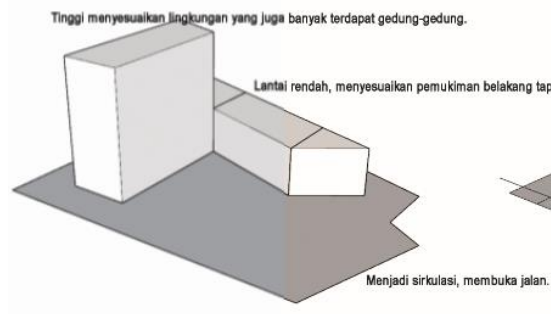

4. Bagian barat dibuat terbuka sebagai akses kendaraan, merespon jalan kecil yang berhimpitan dengan tapak

\section{Dibuat undakan untuk menyesuaikan human scale}

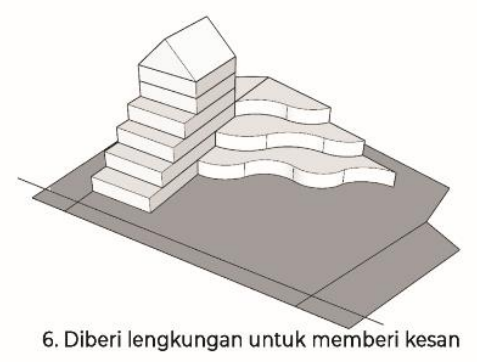

dinamis agar bangunan tidak terlihat formal.

Gambar 3. Proses Gubahan Sumber: Penulis, 2019

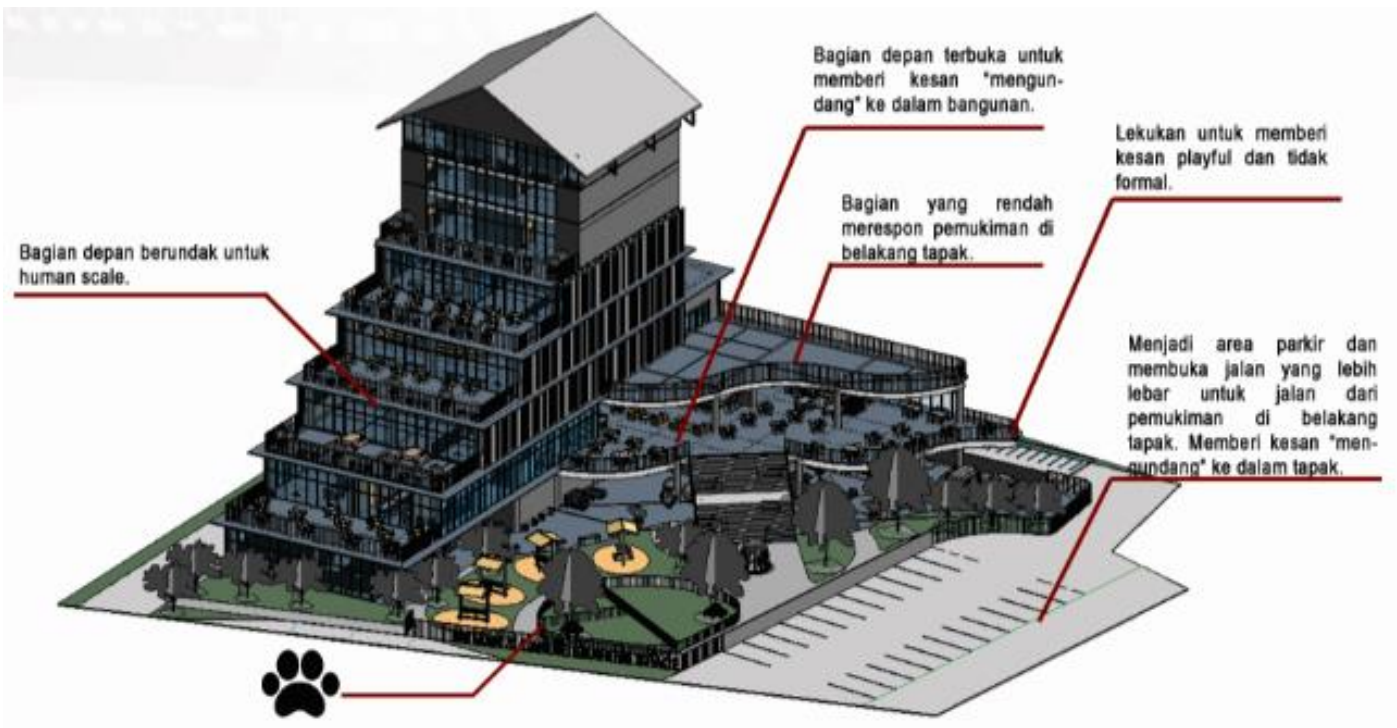

Gambar 4. Konsep Bentuk Bangunan Sumber: Penulis, 2019

Bangunan ini memiliki konsep "playful" dan menjadi "a big playhouse for dogs". Bangunan dibuat dengan material-material yang juga banyak digunakan di bangunan sekitarnya seperti aluminium dan kaca. Bentuk bangunan menyesuaikan tapak dengan diberi ketinggian dengan merespon area yang berhimpitan dengan tapak. Bangunan terbentuk menjadi 2 bentuk massa yang digabung. Massa pertama dengan ketinggian 8 lantai dan massa kedua memiliki ketinggian 3 lantai. Massa pertama dibentuk berundak untuk menyesuaikan human scale dan menggunakan atap pelana untuk memberi kesan seperti "rumah". Massa kedua yang berhimpitan dengan massa pertama memiliki bentuk dasar segitiga yang salah satu sisinya diolah menjadi bergelombang untuk memberi kesan "playful". 
Lantai dasar dan lantai 2 dibuat terbuka dan dapat diakses langsung dari lantai dasar tanpa melalui pintu atau pembatas dinding bertujuan untuk memberi kesan "welcoming" dan membuat ruang luar dan dalam terasa menyatu. Area ruang luar diberi batas dengan area parkir dengan dinding setinggi 1 meter dan area sekelilingnya dengan railing, ini bertujuan agar para pengunjung dapat membiarkan anjing peliharaan mereka bermain bebas tanpa menggunakan tali pengaman dengan rasa aman dan tidak perlu takut anjingnya akan berlari ke jalan raya yang berbahaya serta memiliki resiko kecelakaan. Pet shop diletakan di bagian tertutup di depan karena alasan keamanan, serta menggunakan material kaca untuk display barang ke arah luar. Di dalam pet shop terdapat gudang khusus untuk menyimpan stok barang pet shop tersebut. Ruang utama di lantai dasar ini adalah ruang komunal yang luas dan dilengkapi area duduk. Ada area duduk dengan sofa, ada yang terdiri dari meja kecil dan bangku, ada meja panjang dengan bangku, dan ada bangku-bangku individual untuk pengunjung duduk sendiri. Terdapat juga 2 ruang serbaguna yang dapat disewakan untuk acara-acara seperti gathering, hari ulang tahun, dan lain-lain.

Lantai 2 adalah restoran dan kafe. Terdapat meja-meja makan, booth, dan sofa yang nyaman untuk bersantai. Tangga utama dari lantai dasar ke lantai 2 merupakan tangga selebar 8 meter dengan bangku-bangku pada beberapa area di sisi-sisinya yang dapat digunakan pengunjung untuk duduk-duduk menghadap ke area terbuka. Lantai 3 merupakan area bermain dalam ruangan untuk anjing. Ruangan ini dibagi lagi menjadi 4, yaitu area bermain anjing kecil, sedang, besar, dan campuran. Ruangan dibatasi dengan railing. Pembatasan ruangan ini dilakukan untuk menjaga keamanan setiap anjing karena ada kemungkinan anjing yang lebih besar menggigit anjing yang lebih kecil. Untuk area campuran terdapat area duduk untuk pengunjung yang menunggu anjingnya bermain.

Lantai 4 adalah area kolam renang untuk anjing. Selain berlari dan bermain di area bermain lantai 3, anjing peliharaan pengunjung juga dapat menikmati bermain air dan berenang di lantai ini. Lantai ini dilengkapi juga dengan area duduk untuk pengunjung. Di lantai 5 adalah area grooming atau perawatan. Lantai ini memiliki area resepsionis atau area pendaftaran untuk perawatan dan penginapan di dog hotel. Terdapat juga area duduk atau ruang tunggu untuk pengunjung. Di depan ruang perawatan, terdapat ruang bermain anjing yang terbagi menjadi 2 , satu untuk anjing yang belum melakukan perawatan, satu lagi untuk anjing yang sudah melakukan perawatan. Ruang bermain ini dibatasi dengan railing. Berhimpitan dengan ruang bermain adalah area perawatan di mana anjing dimandikan, dibersihkan, maupun perawatan rambut.

Lantai 6 dan 7 adalah ruang "kamar" dari dog hotel. "Kamar" yang tersedia adalah ruanganruangan kecil berukuran $2 \times 2 \mathrm{~m}$ dan 1,5 × $2 \mathrm{~m}$ yang masing-masing dilengkapi dengan kasur anjing, toilet pad, dan mainan. Di lantai paling atas atau lantai 8 terdapat ruang karyawan, kantor pengelola, dan gudang. Terdapat juga area untuk meletakan reservoir atas dan outdoor AC. Pada bagian tower bangunan terdapat sebuah core yang digunakan sebagai sirkulasi tangga darurat, pit lift, void untuk utilitas listrik dan air, serta ruang AHU. Untuk di bagian timur dan barat bangunan yang terdapat tangga sebagai sistem sirkulasi vertikal dan juga dapat digunakan untuk evakuasi kebakaran. Lantai basement digunakan hanya untuk ruang-ruang utilitas seperti ruang pompa, ruang GWT, ruang STP dan RTP, ruang panel, dan ruang kontrol. Ruang-ruang luar di setiap lantai pada bangunan ini dimanfaatkan sebagai area duduk dan juga area penghijauan dengan tanaman pot. Ruang luar dibatasi dengan curtain wall dan diberi pintu sebagai akses.

Sirkulasi pada bangunan ini dibuat besar karena sesuai dengan namanya, pengunjung diperkirakan akan membawa anjing peliharaan mereka dan anjing kadang dapat menjadi sangat aktif bergerak, diharapkan dengan sirkulasi yang cukup besar, hal itu tidak mengganggu kenyamanan pengunjung, baik yang datang dengan membawa anjingnya ataupun tidak. 


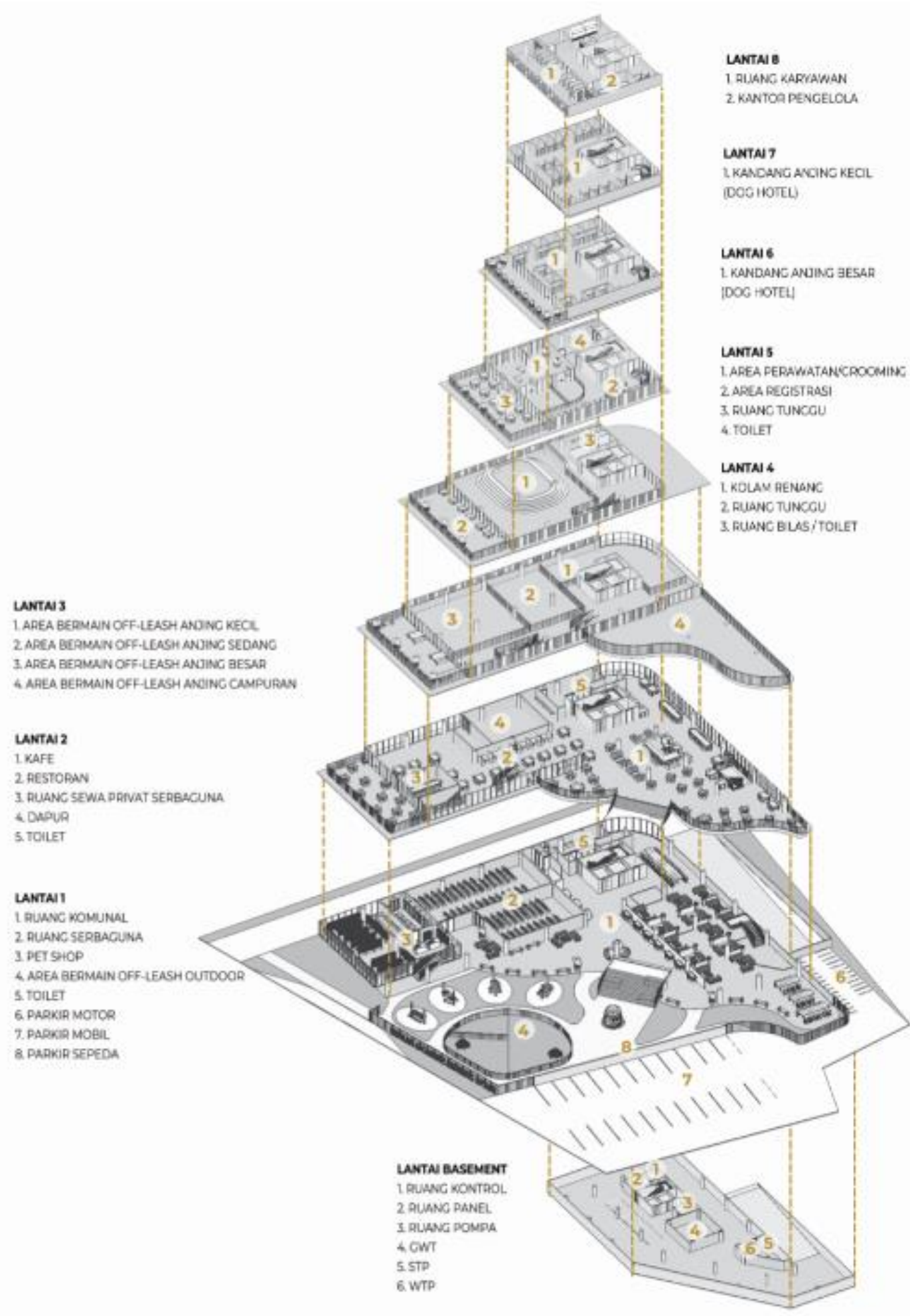

Gambar 5. Denah Exploded

Sumber: Penulis, 2019

Material yang digunakan untuk konstruksi bangunan adalah beton, sementara untuk fasad banyak menggunakan dinding bata polos, dinding kaca, second skin dari aluminium, dan railing aluminium. Bahan-bahan tersebut dipilih untuk menyesuaikan bangunan di sekitar kawasan. Untuk perkerasan di lansekap digunakan konblok dan grass block agar tetap dapat menyerap air. Penggunaan material kaca bertujuan untuk memberi pencahayaan alami ke dalam ruangan 
pada bangunan. Pada beberapa lantai, dinding pada sisi kanan dan kiri ruangan merupakan dinding dengan ketinggian $120 \mathrm{~cm}$, tidak menggunakan dinding setinggi 4 meter. Hal ini dilakukan untuk memberi sirkulasi udara alami pada ruangan dan tidak menggunakan pengudaraan buatan (AC). Second skin aluminium diletakan di depan dinding bata yang setinggi $120 \mathrm{~cm}$ agar menjamin keamanan pengunjung dan anjingnya, namun tetap memberi pengudaraan alami sehingga tidak membutuhkan pengudaraan buatan. Atap yang digunakan untuk bagian tower dari bangunan adalah atap pelana dengan tujuan agar bangunan terlihat lebih informal dan berkesan seperti "rumah". Material yang dipilih untuk atap adalah asphalt shingles. Untuk lantai digunakan ubin berwarna abu-abu untuk menyamarkan jika ada debu atau kotor. Bentuk yang ada di sekitar tapak juga merupakan bentuk-bentuk geometri. Karena bangunan ini bertujuan untuk menciptakan sebuah ruang yang santai, maka bentuk disesuaikan dengan dibuat lebih dinamis agar memberi kesan informal.

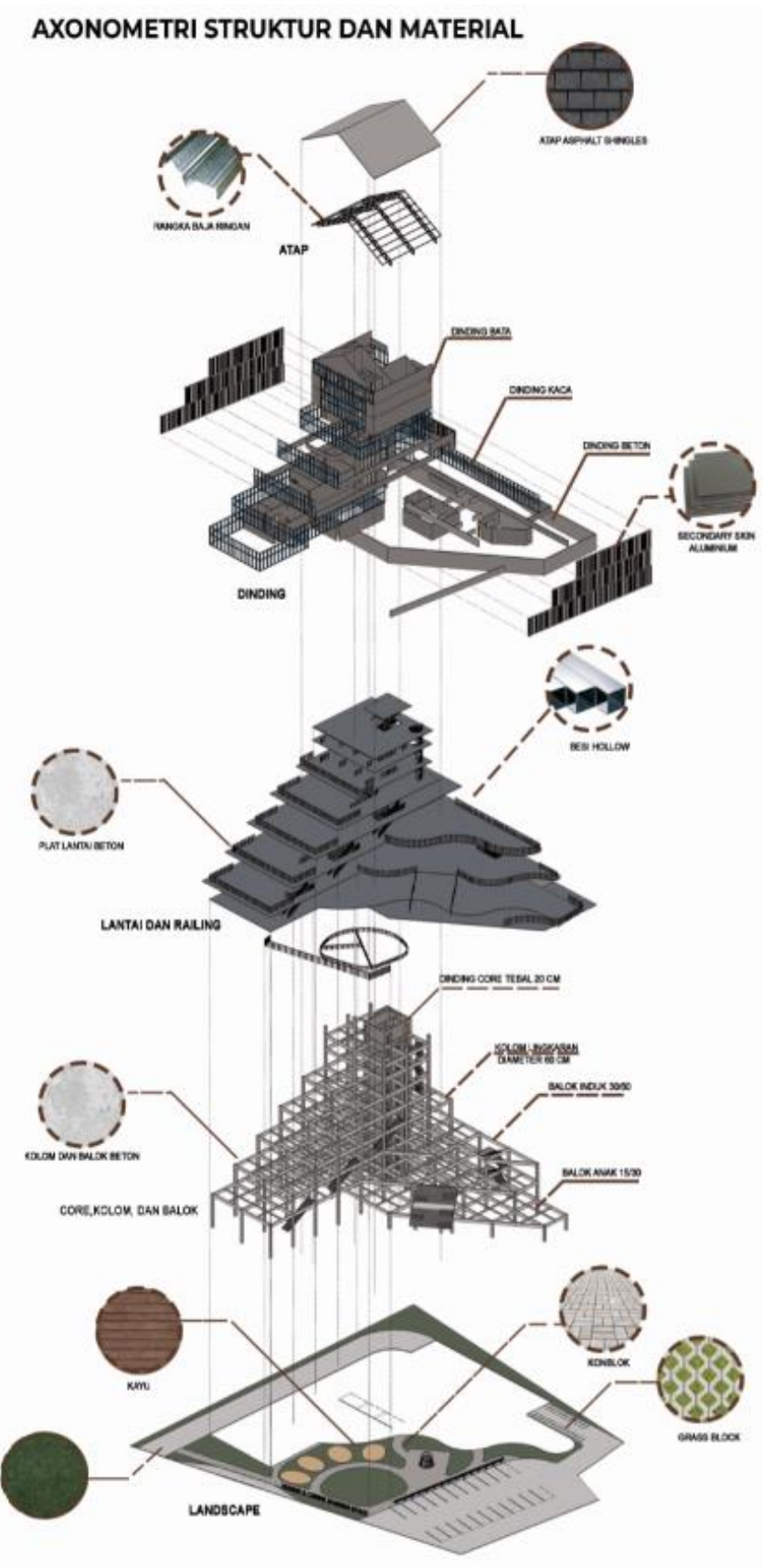

Gambar 6. Axonometri Struktur dan Material Sumber: Penulis, 2019 


\section{KESIMPULAN DAN SARAN}

Setelah melakukan kajian terhadap permasalahan ruang untuk anjing dan manusia, terdapat beberapa kesimpulan yang disampaikan, di antaranya adalah fungsi dan konsep ruang yang dibutuhkan untuk para pecinta anjing untuk bisa bermain dan menghabiskan waktu luang bersama anjing peliharaannya tanpa ada batasan, fasilitas yang dibutuhkan untuk membuat bangunan menjadi ruang yang ramah anjing, serta lokasi tapak yang dipilih melalui analisa kawasan, menjawab kebutuhan ruang ketiga sebagai rekreasi yang ditujukan untuk para pecinta anjing, dimana di Jakarta tidak banyak ruang publik yang dapat dimanfaatkan pengunjung dengan anjing peliharaannya secara bersama-sama.

Dengan adanya proyek ini diharapkan dapat memberikan manfaat dengan menghadirkan sebuah ruang ketiga yang dapat digunakan bersama-sama secara bebas, bukan hanya bagi manusia, namun juga bagi anjing peliharaan, sehingga menjadi third place yang selalu dikunjungi masyarakat sebagai area rekreasi yang menurunkan tingkat stress karena rutinitas sehari-hari. Selain itu, bangunan ini juga diharapkan menginspirasi pihak lainnya untuk menyediakan ruangruang publik lainnya yang menjadi third place dan menambah fasilitas publik yang ramah anjing, tentunya disarankan dengan adanya analisis dan penelitian lebih lanjut tentang kebutuhankebutuhan ruang publik bagi anjing peliharaan dan pemiliknya, sehingga manfaat-manfaat yang ada untuk manusia, anjing, dan komunitas dari ruang publik yang sejenis ini semakin dapat dirasakan.

\section{REFERENSI}

Akcan, E. (2018). Open Architecture: Migration, Citizenship and the Urban Renewal of BerlinKreuberg by IBA-1984 / 87. Birkhauser.

Dogsrkings (2017). Jakarta Indonesia Free Directory For Dogs, K9, Pets, Canines, Dogs \& Puppies. Jakarta: Petrkings.

Dog and Cat Management Board (2013). Unleashed: A Guide to Successful Dog Parks. Diakses pada 25 Agustus 2019, dari www.dogandcatboard.com.au

Dotson, M. J., \& Hyatt, E. M. (2008). Understanding dog-human companionship. Journal of Business Research, 457-466.

Pet, H. (2019). Differences Between Dogs and Cats: Learn What Makes Each One Special. Diakses pada 9 Agustus 2019, dari https://www.hillspet.com/petcare/resources/differencesbetween-cats-and-dogs

Lovers, J.D. (2017). Pendataan Pemilik Anjing untuk Pengembangan Aplikasi E-Dogs. Jakarta Dog Lovers. Diakses pada 9 Agustus 2019, dari https://www.jakartadoglovers.com/blog/pendataan-pemilik-anjing/

Meyer, I. and Forkman, B. (2014). Dog and Owner Characteristics Affecting the Dog-Owner Relationship. Journal of Veterinary Behavior 9, 143-150.

Oldenburg, R. (1989). The Great Good Place: Cafes, Coffee Shops, Community Centers, Beauty Parlors, General Stores, Bars, Hangouts, and How They Get You Through the Day. New York: Paragon House.

Perkumpulan Kinologi Indonesia (2015). Populasi Anjing Ras 2014. Jakarta: The All Indonesia Kennel Club. 
